\title{
The European Forum for All Psychiatric Trainees
}

\author{
Michael van Beinum, David Castle, and Mary Cameron, European Working Party \\ of the Collegiate Trainees Committee
}

The second European Trainees Forum (van Beinum, 1992) met in the Netherlands in March 1993. Training issues were discussed by delegates from the UK, Ireland, the Netherlands, Denmark, Sweden, Norway, Germany, Belgium, Finland, Portugal, and Switzerland. A number of training topics were specifically addressed by the Forum, and a statement unanimously agreed on each of these.

\section{Aims and structure of the Forum}

The aims of 'The European Forum for all Psychiatric Trainees' are to: represent the view of all psychiatric trainees in Europe; gather the views of trainees in psychiatry on their own training; promote the formation of national psychiatric trainees organisations; provide an informed voice of psychiatric trainees on training matters to psychiatric training organisations, both nationally and at a European level; and to inform trainees of the conditions of training in member states.

Representation to the Forum is by two trainees representing their training organisation per country. Where feasible one should represent child and adolescent psychiatry and one adult psychiatry trainees. The chair and secretary of the Forum rotates, and is held by the trainees' organisation that hosted the previous Forum.

The secretariat to the Forum is provided by the Dutch Trainees' Organisation (SAP), who will act as a post box and distribute information, as well as lend assistance to the organisation of future Forum meetings.

\section{Trainee organisations}

A review of trainee organisations in Europe revealed a wide variation. Only three countries have a trainee organisation equivalent to the UK CTC - Denmark, The Netherlands and Ireland. These countries also have strong training organisations equivalent to the Royal Colleges, with a separate trade union organisation, such as the British Medical Association. In the remaining countries there is only a trade union organisation, with a confusing picture with regard to establishing standards of training. Juniors in the latter countries are often reluctant to speak out about their own training, as there are strong hierarchical systems and people fear being scapegoated.
The Forum sees it as vital to have a national trainees' organisation for psychiatric trainees in each European country, which is representative of trainees, which has close contact with and the support of the professional psychiatric organisation of that country, and which can represent the viewpoint of the trainees in all aspects of their training. It is therefore very encouraging to learn that in a number of countries where no such organisation yet exists, active steps are being taken to establish one.

\section{Child and adolescent psychiatry}

Training varies widely across Europe. In some countries it is possible to train as a child psychiatrist with no clinical exposure to adult psychiatry at all, and the Forum felt this would undermine the position of the child and adolescent psychiatry specialist, who should have a breadth of training sufficient to deal both with mental illness in parents of child clients and with the developmental continuities as disturbed children grow up into disturbed adults. The Forum agreed that:

"We acknowledge that there are two European Monospecialist Sections within the psychiatric field. We feel as psychiatric trainees that these two specialities are closely linked, and we would therefore as the European Forum for all Psychiatric Trainees recommend that there be adequate theoretical education for child psychiatrists in general psychiatry too. We would also recommend that there be a minimum of one year experience in the field of general psychiatry for child psychiatry trainees. Similarly for general psychiatry trainees we would recommend a period of practical experience in child psychiatry. This could be obtained in a variety of settings depending upon the structure of training in different countries."

\section{Psychotherapy training}

This, like child and adolescent psychiatry training, varies widely across Europe. Some countries, such as The Netherlands, see it as an essential component of training that every psychiatrist has a personal therapeutic experience along psychodynamic lines of at least 50 hours. Other countries, such as France, require neither a theoretical training, nor any supervision of one's own cases, nor any personal therapeutic experience for the training of a psychiatrist. The Forum unanimously agreed the following statement:

"A working knowledge of psychotherapy is an integral part of being a psychiatrist. Training must reflect this. A basic 
training must include supervision by qualified therapists of clinical practice, as well as theoretical training in a broad range of psychotherapies. Skills should be gained in at least one of the forms of psychotherapy. Sufficient experience should be gained in the other psychotherapies to allow the trainee to assess a patient as to their suitability for referral to a specialist psychotherapist. A personal psychotherapeutic experience is seen as a valuable component of training and is strongly recommended. Training schemes should provide an opportunity for this."

\section{Maintaining high professional standards}

Only some European countries have a higher professional exam, and the Forum felt that the provision of high quality training schemes with continual assessment of both the training scheme and the trainee, with frequent feedback on progress, is far more important. The role of a tutor, independent of the trainee's consultant, is seen as essential. Equally, inspection visits of training schemes to assure a high standard of clinical practice is seen as being extremely important. The Forum agreed that:

"In order to assure the quality of psychiatric training we feel there needs to be an evaluation of both theoretical knowledge and clinical skills. An important component of evaluation and training should be continuous and adequate supervision of trainees. This evaluation should be of both the training scheme and of the trainee. We feel that this is best undertaken by a central, independent professional body which continuously evaluates standards of training. This body should include trainee representatives. While we support the concept of minimum European standards of training for psychiatry, we as an organisation do not feel this is best undertaken by a common European examination."

\section{The future}

The European Monospecialist Section in Psychiatry (UEMS) had recently set up, at the request of the European Commission, a European Board in Psychiatry, which would make recommendations for the training of psychiatrists in all EEC countries, at which the Forum has been granted observer status. The next meeting of the European Forum for All Psychiatric Trainees will be hosted by the Irish trainees in 1994. Future agenda items include the place of both research and neurology in the training of psychiatrists.

\section{Reference}

van Beinum, M. (1992) European Trainees Conference. Psychiatric Bulletin, 17, 96-97. 